\title{
Bilateral pallidostriatal necrosis caused by a wasp sting: a clinical and pathological study
}

\author{
J Gállego, T Tuñón, G Soriano, G Delgado, F Lacruz, J A Villanueva
}

\begin{abstract}
A previously healthy man developed an acute encephalopathy with coma after a single wasp sting on his chin. Brain CT showed bilateral pallidostriatal radiolucencies. He died 72 hours after the sting with no evidence of primary cardiorespiratory failure or allergic reaction. Pathological findings were bilateral pallidostriatal necrosis and diffuse neuronal damage in the frontal, temporal, and parietal cortex. The neurotoxic effect of the poison, together with a hypersensitivity are the most likely explanations for this unusual encephalopathy.
\end{abstract}

(F Neurol Neurosurg Psychiatry 1995;58:474-476)

Keywords: wasp sting; bilateral pallidostriatal necrosis

Wasp stings are an exceptional cause of bilateral symmetric striatal necrosis. Castaigne et $a l^{l}$ published a clinical and pathological study of a case in 1962. To our knowledge, only two other cases have been subsequently published. ${ }^{23}$ We report the clinical and pathological study of a patient who, after a wasp sting on his chin, developed an encephalopathy that proved fatal after 72 hours. The underlying neuropathology was a bilateral pallidostriatal necrosis with extensive lesions of the cerebral cortex.

Hospital de Navarra, Pamplona, Spain Servicio de Neurología J Gállego

G Soriano

G Delgado

F Lacruz

J A Villanueva

Servicio de Anatomia Patalogica

T Tuñón

Correspondence to: Dr J Gállego, Servicio de Neurologia, Hospital de Navarra. I runlarrea 3, 31008 Pamplona, Spain

Received 31 May 1994 and in revised form 14 November 1994 Accepted for publication 18 November 1994

\section{Case report}

A 72 year old man, previously in good health, complained of severe headache and unsteadiness a few minutes after being stung on the chin by a wasp. The first clinical examination carried out in another hospital one hour after the sting showed a stuporous patient with weakness of the right arm and leg and bilateral Babinski's sign. Meningeal signs were not present. A local swelling appeared at the site of the sting. There were no signs of cardiovascular failure or electrolytic disturbances. On admission to our hospital 24 hours after the sting, the patient was in a coma with normal respiration. Reactive pupils and oculocephalic responses were present bilaterally. $\mathrm{He}$ responded to noxious stimuli with bilat- eral decerebrate rigidity. Tendon jerks were brisk and symmetric. The rest of the physical examination was normal except for an axillary temperature of $38^{\circ} \mathrm{C}$. The blood count and electrolytes, blood clotting tests, and serum creatinine, glucose, creatine phosphokinase, lactic acid, pyruvic acid, transaminases, and variables in urine were within normal limits. An ECG chest radiograph, cerebral CT, and CSF were all normal. Repeated CT 48 hours after the sting showed low density of both lenticular nuclei, most pronounced in the left globus pallidus (figure, A). The patient died suddenly 72 hours after the sting with no signs at any time of cardiorespiratory failure or metabolic derangements.

A full necropsy was carried out immediately after death. The abnormal pathological findings were confined to the cerebrum. No other organ showed lesions that could indicate a hypersensitivity reaction, such as oedema, collections of eosinophils, or mastocytes in the skin and lungs, or bronchospasm. The brain weighed $1430 \mathrm{~g}$ and had been fixed in $10 \%$ formaldehyde for several weeks before detailed examination. Tonsillar herniation was found. Before dissection it was noted that the brain had a softer consistency than normal. Macroscopically there were bilateral cavitations of the globus pallidus and softening of the putamen and caudate nuclei (figure, B). Histologically the globus pallidus was completely destroyed. The neurons of the putamen, caudate nucleus and frontal, parietal and temporal cortex were shrunken, with eosinophilic cytoplasm and pyknotic nuclei. The frontal, parietal, and temporal cortex showed vacuolation, spongiform changes, and eosinophilic shrunken neurons. The subcortical white matter underlying the damaged areas of the cortex showed pallor of the myelin. Capillaries were congested in the damaged areas and contained numerous polymorphonuclear leucocytes in Virchow Robin's space, which also invaded the neighbouring parenchyma at some points. There were no capillary proliferations or lymphoplasmocytic infiltrates. The occipital cortex and the hippocampus were undamaged, as were the thalamus, midbrain, pons, medulla oblongata, cerebellum, mamillary bodies, 


\begin{abstract}
(A) $C T$ showing asymmetric low density areas in the pallidostriatal region, more pronounced on the left side. (B) Axial section through the brain at the level of the basal ganglia. There is softening of the putamen. Caudate nuclei and globus pallidus were destroyed.
\end{abstract}

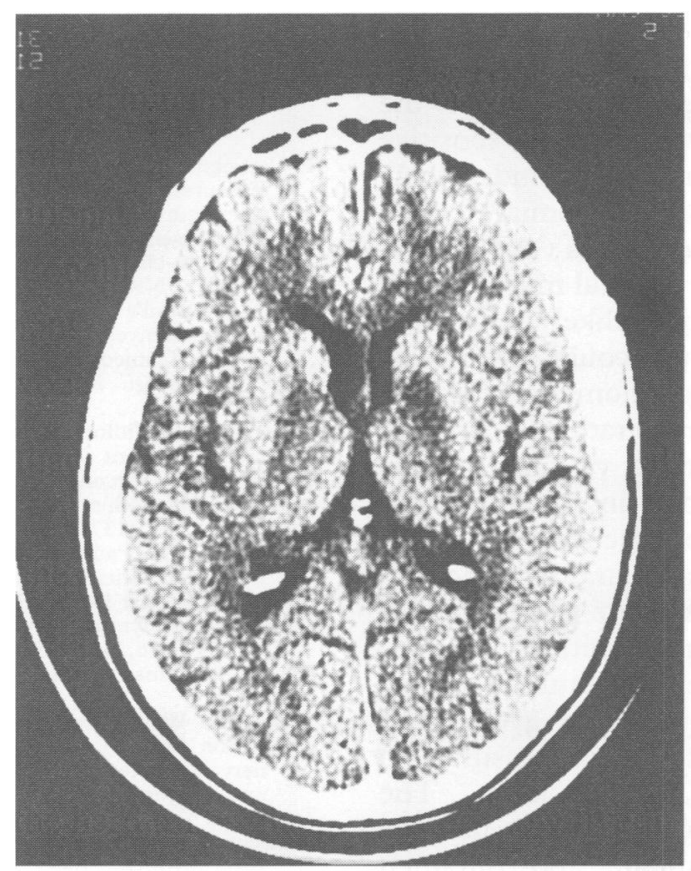

(A)

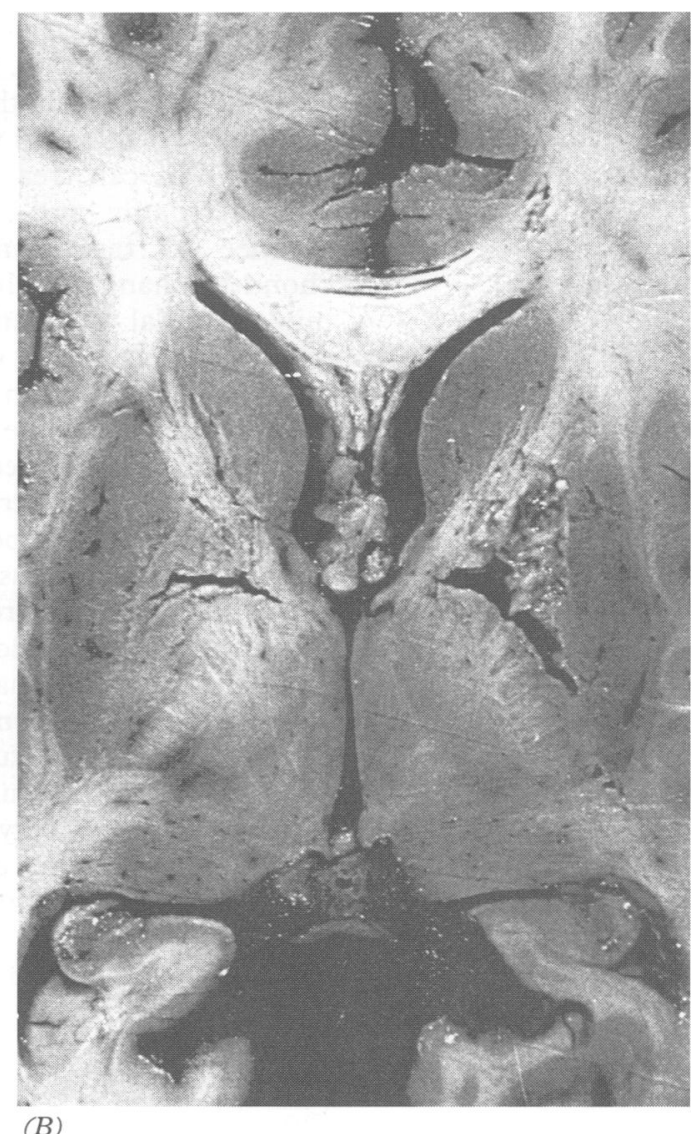

(B) spinal cord, optic nerve, meninges, and peripheral nerves. Histological, histochemical, and electron microscopic studies of skeletal muscle were all normal, with no indication of mitochondrial damage.

\section{Discussion}

Neurological complications after a wasp sting are unusual. Polyradicular neuritis indistinguishable from Guillain-Barré syndrome ${ }^{4}$ and oculomotor disturbances similar to those of ocular myaesthenia gravis ${ }^{5}$ have been described 24 hours after a wasp sting. Lesions of the CNS system are rare. Castaigne et al published the postmortem study of a 29 year old woman who died after 55 days in a coma as a result of a wasp sting. They found corticostriatal necrosis without involvement of the hippocampus, globus pallidus, or cerebellum, together with laminar necrosis of the cerebral cortex and pronounced capillary proliferation. There were severe necrotic lesions in the putamen and less severe lesions in the caudate, thalamus, and red nucleus. ${ }^{1}$ The authors suggested three causal factors: ischaemic, anoxic, and allergic. We know of another report, published in Russian, of a patient who died two weeks after a wasp sting on his hand. The clinical picture was characterised by systemic symptoms due to anaphylactic shock. Parkinsonism developed during the subsequent hours with signs of radicular and spinal involvement. The authors reported severe lesions of vital organs caused by allergic reactions, of both the immediate and delayed types. The most important finding in the nervous system was bilateral pallidal necrosis with less profound lesions in the substantia nigra. ${ }^{2}$

A patient studied by Laplane et $a l^{3}$ had an acute encephalopathy with bilateral hypodense pallidostriatal lesions on CT. The patient, who survived, was found unconscious immediately after the wasp sting and also had convulsive seizures. Furthermore, he had choreic movements during the acute phase of the encephalopathy. Gait disorder and myoclonus lasted for several months, with a slow recovery. He developed a personality disorder with compulsive obsessive behaviour several years afterwards. Gale ${ }^{6}$ reported two patients who had anaphylactic reactions from insect stings, one of them a wasp sting, with severe dystonia and akinetic mutism. In one patient the CT showed a border zone infarct. Ischaemia and hypoxia were the mechanisms involved in the pathogenesis. There was no necropsy material available. Behan studied a man who developed a neurological picture compatible with multiple sclerosis and hypertrophic neuropathy after an influenza like illness followed by a bee sting. ${ }^{7}$ The role of wasp stings on the triggering of diseases such as multiple sclerosis, Guillain-Barré syndrome, or motor neuron disease has not been determined. ${ }^{8}$

Our patient showed clinical and pathological features similar to the patient reported by Castaigne et $a l^{1}$ although with the additional involvement of the globus pallidus and with more acute changes within 72 hours. His sudden death was caused by increased mass effect with tonsillar herniation and 
subsequent cardiorespiratory arrest. The most likely pathogenic mechanism in our case is the toxic effect of the wasp poison on the CNS in a person who was especially sensitive to it. We can reasonably exclude toxic encephalopathy and hypoglycaemia. ${ }^{910}$ The absence of ragged red fibres and mitochondrial changes in the skeletal muscle make mitochondrial cytopathy unlikely, although the toxic agent of the wasp could give rise to an energy deprivation phenomenon, caused by interruption of the respiratory chain and the appearance of necrotic vascular lesions similar to those described in mitochondrial cytopathies. ${ }^{11}{ }^{12}$ A hypoxic-ischaemic mechanism seems unlikely as a haemodynamic failure or respiratory distress were not present at any time. The histological pattern did not suggest a hypoxic-ischaemic picture. Furthermore, Ammon's horn, dentate gyrus, and Purkinje cells, structures very sensitive to anoxia and ischaemia, were intact. The increased susceptibility of the globus pallidus compared with the caudate and putamen nucleus is similar to the findings from other toxic encephalopathies such as carbon monoxide intoxication. ${ }^{13}$ The pathological findings in our case exclude an anaphylactic response as the cause of death.

The pathogenesis of acute encephalopathy caused by a wasp sting is unknown. The poisons from wasps and bees contain biogenic amines and toxic peptides such as apamine and melitine, which have been shown to be neurotoxins. ${ }^{14}$ The mechanism by which they might produce a neuronal lesion, presumably at a molecular level, however, remains a mystery.
We are grateful to Dr J Gállego Berenguer for his expert comments and skilful assistance and to Carol Elsden for translation of the manuscript.

1 Castaigne P, Bertrand I, Buge A, Godet Guillain J, Escourolle R, Martin $M$. Coma prolongé secondaire à une piqûre d'insecte nécrose symétrique des putamens ramollissement laminaire cortical étendu. Etude ramollissement laminaire cortical étendu. Etude
anatomo-clinique. Rev Neurol (Paris) 1962;107:401-16.

2 Bogolepov NK, Luzhetskaya TA, Fedin AI, Artomasova AV, Vasil'ev PN, Grigorevskaya NG. Allergic encephalomyelo-polyradiculoneuritis due to wasp stings. Clinico pathomorphological report. Zhurnal Nevropatologii $i$ Psikiatrii im SS Korsakova 1978;78: 187-91.

3 Laplane D, Widlocher D, Pillon B, Baulac M, Binoux F. Comportement compulsif d'allure obsessionelle par nécrose circonscrite bilatérale pallido-striatale. Encéphalopathie par piqûre de guêpe. Rev Neurol (Paris) 1981;137:269-76.

4 Bachman DS, Paulson GW, Mendell JR. Acute inflammatory polyradiculoneuropathy following hymenoptera stings. $\mathscr{F} A M A$ 1982;247:1443-5.

5 Brumilk J. Myasthenia gravis associated with wasp sting. ЭAMA 1976;235:2120-1.

6 Gale AN. Insect sting encephalopathy. $B M f$ 1982;284: $20-1$.
choene

7 Schoene WC, Carpenter S, Beham PO, Geschwind N. Onion bulb formations in the central and peripheral nervous system in association with multiple sclerosis and hypertrophic polyneuropathy. Brain 1977;100: 755-73.

8 Behan PO, Behan WMH. Insect sting encephalopathy.

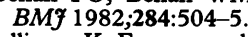

9 Jellinger K. Exogenous lesions of the pallidum. In: Vinken PJ, Bruyn GW, Klawans HL, eds. Handbook of clinical neurology 49. Amsterdam: Elsevier Science Publishers, 1986:465-91.

10 Jellinger K. Exogenous striatal necrosis. In: Vinken PJ, Bruyn GW, Klawans $\mathrm{HL}$, eds. Handbook of clinical neurology 49. Amsterdam: Elsevier Science Publishers, 1986:499-518.

11 Delgado $G$, Gállego J, Tuñón $T$, Zarranz JJ, Villanueva JA. Necrotising haemorrhagic encephalomyelopathy in an adult: ? Leigh's disease. $\mathcal{F}$ Neurol Neurosurg Psychiatry 1987;50:224-7.

12 Cavanagh JB. Necrotizing hemorrhagic encephalomyelopathy in an adult: ? Leigh's disease. $\mathcal{f}$ Neurol Neurosurg Psychiatry 1988;51:1245-6.

13 Norenberg MD, Bruce Gregorios J. Nervous system manifestations of systemic disease. In: Davis RL, Robertson DM, eds. Textbook of neuropathology. Baltimore: Williams, 1991:461-518.

14 Piek T. Neurotoxic kinins from wasp and ant venoms. 